Parkhurst, G., Meek, S. (2014). The Effectiveness of Park-and-Ride as a Policy Measure for more

Sustainable Mobility. Chapter 9 in Ison, S. \& Mulley, C. (Eds) Parking Issues and Policies. Emerald, 185-211.

Contact email: graham.parkhurst@uwe.ac.uk

\title{
The Effectiveness of Park-and-Ride as a Policy Measure for more Sustainable Mobility
}

\author{
Graham Parkhurst \\ Centre for Transport and Society, University of the West of England, Bristol BS16 1QY, UK \\ Stuart Meek \\ Southern Rail, Palestra, 197 Blackfriars Road, London SE1 8NJ, UK
}

\section{Purpose}

The chapter provides a general review of the policy debate around the provision of formal Park-andRide (P\&R) facilities and the empirical research evidence about travellers' responses to the opportunities they present, drawing on evidence from the United Kingdom and the Netherlands. The effects of the schemes on road traffic and car dependence are considered.

\section{Design/Methodology/Approach}

The different ways in which private vehicles and public transport are combined during journeys are reviewed. The position of P\&R is considered as a modal variant within a 'socio-technical system' competing with the more established journey options of fully-private and fully-public transport. Scenarios which can maximise the traffic reduction and sustainable development potential of $P \& R$ are examined.

\section{Findings}

The review of the policy context establishes that a range of policy objectives are conceived for P\&R depending on different professional and citizen perspectives. There is partial understanding amongst local authorities about the effectiveness with which P\&R addresses the range of objectives in practice. The key travel behavioural findings are that only a portion of P\&R users' car trips are shortened. Hence, overall increases in car use occur, combined with overall reductions in public transport use, and in some cases less active travel. Where dedicated public transport services are operated, these are also a further source of additional traffic.

\section{Practical implications}

P\&R implementations are generally successful where they are explicitly for providing more parking for economic growth or traffic management reasons, rather than to enhance sustainable mobility. The essential conditions for traffic reduction to occur in future are a strategic subregional integrated parking and public transport strategy which achieves interception of car trips early and ensures public transport services remain attractive for a range of access modes.

\section{Originality/value}

The chapter provides a synthesis of work by a number of leading authors on the topic and includes elements of originality in the combination of the established knowledge, the addition of novel insights, and in overall interpretation.

\section{Keywords}

Park-and-Ride, strategic transport planning, public transport, parking, automobility, sustainable mobility 


\section{Introduction}

In its most simple terms, a park and ride (P\&R) journey occurs when a private vehicle, normally a car, is parked at a public transport node, to enable the use of a public transport service for part of the journey. The modal interchange is made either because the traveller wishes to use the public transport service as the primary mode for the journey, but a private car is judged the most effective way to access the public transport network, or, conversely, the car is the preferred primary mode for the journey, but advantages are perceived if the final part of the journey is made by public transport.

Within this broad description, a range of $P \& R$ phenomena exist, but the most common kinds are parking at rail stations and dedicated bus $P \& R$. Rail $P \& R$ itself is a diverse phenomenon, serving journeys of a range of lengths, from local to intercity. Depending on network configuration and service patterns, a specific station car park may be oriented towards opening up a whole network of destinations or towards a particular city. Moreover, the interchange may occur at various points in the journey. Where it is early, the car acts as a station access mode; where it is very late, the railway is in effect a shuttle service within the destination area. When it provides this latter function, rail $P \& R$ operates in a similar mode to most bus P\&R schemes, which are oriented towards local or regional demand for travel to a core city and typified by interchange relatively late in the overall trip. One key difference, however, is that rail $P \& R$ is typically an add-on to an existing public transport service, whereas bus P\&R usually involves a dedicated car park on the periphery of the urban area and a dedicated shuttle bus service which is additional to the existing bus network.

The current chapter focusses on $P \& R$ facilities with a subregional function, as this type of scheme features more intense and direct interactions with the urban parking market. Within this focus there is an emphasis on the empirical evidence about the effects of P\&R policies. As much of this evidence relates to bus-based schemes there is a further pragmatic focus on that mode.

The chapter will begin by examining $P \& R$ as a transport planning practice, through two sections which first consider interchange capacity provision as being variants of a sociotechnical system and then examine the different policy perspectives which can motivate formal P\&R policy implementation. The third and fourth sections in turn then consider the empirical evidence on the behavioural effects of $P \& R$ systems and the implications of that evidence for the wider sustainable development context, including how P\&R might be delivered in ways which achieve enhanced accessibility benefits whilst also reducing total traffic. The chapter concludes by noting that the main contributions of P\&R policy to date have been in the economic and traffic management domains, and by emphasising the key strategic transport planning requirements if $P \& R$ is to make a sustainable mobility contribution.

\section{P\&R Provision as a Sociotechnical System}

As in the case of parking in general, accurate censuses of P\&R supply are hard to conduct, as the facilities are promoted by multiple agencies, are often introduced and then expanded, and may not be formally recognised as $P \& R$, but simply as 'station parking'. However, summary statistics are provided here for two European states to give an indication of scale.

Mingardo (2013) reviewed the development of P\&R in the Netherlands; one of the leading European proponents. The first official P\&R was introduced in 1979 in Schagen, north of Amsterdam. By the end of the 1980s, more than 50 official P\&R facilities were in use and, in 2003, 386 P\&R facilities were in operation in the country. 
For the UK, Pickett and Gray (1993) estimated that 85,000 official parking spaces throughout the southeast of England potentially served Central London, including those at London Underground stations. However, P\&R trips from those spaces were estimated to account for just $2 \%$ of commuter trips from within Greater London and $8.5 \%$ of those originating outside. Since then policy has increased this supply and parking fees have become an important revenue stream in the operation of UK rail franchises. Many of these journeys are of an inter-regional nature and enable London to function as a megacity: the concentration of commercial and administrative activity in the relatively compact area of Central London would not be possible without a public transport-dominated modal split.

More generally, Clayton, Ben-Elia, Parkhurst and Ricci (2014) record that the UK was one of the countries that pioneered the use of bus-based $P \& R$ in the early 1970s, with substantial investment having resulted in $P \& R$ becoming an important feature of many local transport policies. By 2000 there were 70 sites established and by 2007 there were more than 130 P\&R sites operating in Great Britain, together serving approximately 60 towns and cities across the country. Overall, this capacity is estimated to provide 70,000 parking spaces and to utilise more than 400 buses daily. Annually, bus $P \& R$ has been found to account for 46 million passenger journeys in the UK, and to generate revenues of $f 40 m$ (TAS Partnership, 2007).

The case of Oxford, one of the UK cities with both extensive bus P\&R capacity and restraints on city centre car use, provides an indication of the local significance of this aggregate picture. By 2001 there were approximately 5,000 spaces in five sites and $P \& R$ was the most celebrated feature of local transport policy. The system was providing for around $7 \%$ of trips to the city centre (Parkhurst \& Dudley, 2004: Fig. 1). Whilst not being an insignificant contribution, in practical rather than symbolic terms P\&R was a minor mode, as conventional buses were delivering one-third of travellers and approaching half used private cars.

Moreover, most cities have little or no P\&R capacity. In this context the current scale of supply in the UK is low in overall terms, and there may therefore be considerable potential to promote interchange as a sustainable transport policy.

Within the broad introductory definition of $P \& R$, there are multiple criteria which distinguish different types of P\&R 'system'. These are:

- the relative distance of the modal transfer point from the final destination;

- the mode of transport which is transferred to, with the most common options being bus, light rail, urban/commuter rail and inter-city rail;

- the exclusive or integrated nature of the public transport service, i.e., whether it is solely used by travellers making P\&R trips (which may arise either because it is hard to access the public transport using any other feeder mode or because travellers not arriving by car are deterred as a matter of policy);

- whether the parking capacity is reserved for interchange passengers or shared with other types of parking demand (either simultaneously or at different times);

- the basis for charging for the P\&R facility, which typically amounts to whether the car parking is free or charged, but can involve integration with the public transport user fares. Most important is the relative cost of $P \& R$ use compared with the cost and ease of accessing the destination by car and parking there. These relative costs are variously determined by a mix of public and private sector providers seeking to maximise return on assets or achieve public policy objectives through regulation and price mechanisms.

To expand on the issue of transfer point, Mingardo (2013) takes a strategic spatial-locational focus, categorising the most common P\&R systems in the Dutch context as being: 
- remote, located in suburban residential areas and oriented towards the early interception of commuter trips;

- peripheral, edge of town facilities, with a destination-oriented function, whose aim is to intercept drivers just before their final destinations;

- local, with a 'field function' to intercept drivers on main transport corridors at intermediate points between origin and destination.

A fundamental influence on the decision to change mode, and where that transfer occurs, is the availability of parking ${ }^{1}$. Here it is important to note that proactive $P \& R$ supply policies interact with innovative individual travel behaviour, with $P \& R$ demand and supply showing both formal and informal development. Using a before and after methodology, Heggie and Papoulias (Papoulias and Heggie, 1976; Heggie and Papoulias, 1976) found that $13 \%$ of users of Oxford's first formal bus P\&R were already parking near a bus stop to catch a general-purpose bus service not conceived or marketed as providing a modal interchange offer. On-street parking near suburban railway and metro stations is a widespread phenomenon; generally ignored or tolerated until it conflicts with other parking demands ${ }^{2}$. Indeed, formal $P \& R$ provision policy is strongly driven by the need to dedicate P\&R parking capacity, to avoid such conflicts. Travel to work is a common P\&R journey purpose. In unregulated conditions early-arriving commuters might be expected to occupy, throughout the day, the on-street parking facilities also sought by shoppers. Conversely, where P\&R is being promoted as a policy, there is a need to ensure the capacity provided, often at public expense, is used to facilitate the desired behaviour, and not used as additional parking for activities which happen to be near the public transport node. In a few cases, where P\&R has been promoted through the provision of a public transport journey at a lower fare than the equivalent journey on the public transport system, but accessed on foot, policymakers have sometimes perceived a need to ensure the users of the public transport have in fact arrived by car.

Given that decisions about parking provision and cost can have a significant influence on motorists' choices, studies have sought to identify the theoretically optimal location for P\&R facilities. Horner and Groves (2007), considering rail P\&R in the US, summarise the challenge as seeking to maximise the interception of cars but also intercepting them as early as possible in order to boost rail patronage and traffic reduction, whilst, where possible, achieving secondary socioeconomic objectives, such as locating the facilities at commercial centres which might benefit from the interchange traffic. However, individual travellers may not share these societal benefits. Travellers are more likely to interchange early in the journey if the public transport mode offers an attractive journey time or reliability advantages; attributes often associated with rail systems. Conversely, if the main incentives for $P \& R$ use are scarce or expensive parking at the final destination then travellers may be more oriented towards interchanging late in the journey. As well as city centres, airports provide good examples of the latter market mechanisms, with travellers often being provided with a range of short and long-stay parking and P\&R options, with price declining with distance from the terminal.

\footnotetext{
${ }^{1}$ Except in the case of the variant of P\&R referred to as 'Kiss and Ride' which obviates the need for parking by the traveller being given a lift to the $P \& R$ facility. In this case the key requirement is effective car access to the vicinity of the public transport node.

${ }^{2}$ Another example of the importance of informal interchange arises from the practice of 'Park and Share' (P\&S), which has similarities with P\&R. P\&S involves the pre-arranged meeting of private car drivers at mutually convenient locations in order to carpool, so leaving one or more private cars at the meeting point. The practice has generally been informal and user-arranged, making use of motorway service station car parks and P\&R facilities as well as more ad hoc facilities, such as the kerbside. However, UK local authorities such as Hertfordshire County Council now offer formal coordination and others such as the City and County of Swansea, as well as the Northern Ireland Executive, have provided dedicated car parks. In principle many of the debates around P\&R would also apply to P\&S, however, empirical evidence on its effects of park and share is very limited, and it is therefore beyond the scope of this chapter.
} 
Where $P \& R$ is provided on a rail network, travellers are often presented with multiple $P \& R$ options, sometimes on different lines, and have a choice of interchanging early or late, as well as not at all. In the UK dedicated 'parkway' stations on main lines outside of urban centres served by high frequency express trains and with large parking facilities have been successful at attracting a car-dependent patronage. However, concerns that such facilities could encourage 'railheading' - encouraging motorists to interchange late in order to take advantage of a higher quality rail service but at the expense of extra road traffic - led the authority Transport for London to adopt a policy presumption against P\&R development on the rail networks within the London area (Buxton \& Parkhurst, 2005).

Therefore, P\&R provision is not simply defined by explicit policies on capacity provision and regulations about use, but represents a number of travel practices, influenced by infrastructure provision and social expectation, as well as space-time economics. Considered in terms of a sociotechnical transition, the development of a new P\&R service presents challenges greater than the sum of those associated with the modes being integrated (Parkhurst, Kemp, Dijk, \& Sherwin, 2012). In most developed country contexts, the dominant mobility 'regime' is that of car use, which is generally the most straightforward and obvious mode to use. Car travel requires the lowest cognitive effort for the majority of citizens which are car-oriented, and most transport planners and engineers have traditionally emphasised professional skills and experience in providing for the car. Other transport modes are more likely to be novel and require greater cognitive and physical effort. They exhibit more complexity, have less extensive networks (in both the transport and social senses) and information about the practice and custom of using them is less diffuse. In the case of public transport services, knowledge of custom and practice tends to lie within a parallel, separate sociotechnical culture constituted by providers, mainly public transport operators, and the subgroup of citizens who are their significant users. This knowledge includes procedures and practices ranging from Logistical aspects such as how timetables are read, interconnections made, and the purchase and validity of tickets, through to subtle cultural practices, such as whether it is socially acceptable to eat on a vehicle, talk to fellow passengers, and which seat to occupy on a partially-full vehicle.

$P \& R$ as a form of intermodality seeks to link these different sociotechnical systems in order to offer the benefits of each, but in doing so potentially faces barriers of acceptance from each. The hard engineering aspects can be relatively easy to address, through capital investments in dedicated interchanges, reducing tangible barriers such as physical accessibility. However, the cultural practices of the niche require users to seek and acquire new knowledge and those practices may need to evolve to meet user expectations, to overcome incompatibilities between the regimes. For example, local authorities have needed to respond to the expectation that overnight parking be permitted at $P \& R$ sites, when they were originally intended for day-long trips; that public transport fares for P\&R users travelling in groups should be charged at or close to the individual rate (mirroring the marginal cost of an additional passenger in a car); that high frequency shuttle services should be available into the evening, despite tapering demand. Nonetheless, notwithstanding the apparent complexities presented to the novel user, $P \& R$ is generally simpler to understand and more oriented to the perspective of the habitual motorist than the typical bus network. For all but the smallest towns, the latter generally has a greater variety of routes and often many destinations served from a single bus stop, and often a wider range of fares.

Where $P \& R$ schemes have been most successful, they have generally functioned by adding $P \& R$ capacity to high-status, well-resourced modes such as commuter rail, or by 'mutating' the public transport offer through dedicated bus provision so it delivers a level of service much closer to that of the private car than typically available in that locality. This is generally only possible through the allocation of public subsidy to the operations. Moreover, considerable public sector costs and professional efforts are involved to align and coordinate interests and resources, in order to deliver the infrastructure and services. Such policy construction requires a sharp and distinct policy 'frame', or way of encapsulating a problem and proposed solution (Schön \& Rein, 1994). The narratives 
developed from these frames tend to present strong beliefs and expectations about the potential benefits of $P \& R$ investment and subsidy, typically in the domains of economic promotion or environmental protection. As is often the case when a particular sociotechnical practice such as $P \& R$ is promoted as a revolutionary solution to long-standing problems, rival perspectives drawing on different evidence or interpretations emerge. Combined with a complex policy implementation context, with varied and diverse behavioural responses and outcome consequences, P\&R can be a challenging policy measure to assess. The following section considers further these different perspectives.

\section{Different Perspectives on the Role of P\&R}

As noted in the previous sections, the individual traveller's perspective on P\&R can be characterised as perceiving $\mathrm{P} \& \mathrm{R}$ as an opportunity to:

- avoid constrained parking near the destination, due to scarcity or price,

- avoid unattractive driving conditions en route, as a result of congestion, distance fatigue, or complex navigational requirements,

- retain the benefits of private car use for the first leg of the journey, the origin of which may not be immediately accessible by public transport.

Such perceptions generally occur in the context of a highly automobile society.

The policymaker's perspective is more complex. Indeed there are multiple perspectives which tend to reflect professional orientation:

- A transport planner will emphasise the potential of $P \& R$ to have direct influence on traffic and/or congestion, with the expectation that each of these should reduce. Indirectly, positive consequences for exhaust emissions will be assumed. Successful achievement of traffic reduction may enable the reallocation of road space and land used for parking to other purposes. Due to the potential to influence air quality, environmental health professionals can be expected to take an interest in these outcomes, whilst not necessarily being in a position to influence policy strongly themselves (Olowoporoku, Hayes, Longhurst \& Parkhurst, 2012).

- An economic development professional will regard P\&R as one means of providing and advertising more attractive conditions for car users, to encourage retail customers and other commerce to locate in the city centre. Generally, there will be a preference for P\&R capacity to be in addition to, rather than instead of, city centre parking. Flexibility can however be shown towards the relocation of parking capacity in particular contexts where P\&R is seen to be supporting a strongly business-oriented city centre access and public realm strategy (Parkhurst \& Dudley, 2004).

- The transport operator's perspective will depend on the regulatory regime, but will generally be favourable where $P \& R$ is seen to simplify operations by focussing demand at specific nodes, and to be a means of attracting or retaining customers. Road public transport operators may expect reduced traffic to improve operating conditions for all services.

- Professionals with a specific remit to assess and reduce climate change emissions might be expected to take a more strategic view, examining the system-wide effects, and considering indirect and long-term implications.

Individual perspectives can be assumed to vary according to the spatial extent of competence and responsibility each actor has. A transport planner with a clear remit for a particular urban area may have little professional regard for any traffic overspill consequences, provided objectives within the city are met. Similarly local economic development professionals will have a remit to focus on city or 
subregional performance, rather than total national productivity or the needs of other neighbouring cities. Importantly, some of the objectives of the different professionals will coincide, but some will be in conflict.

Dijk and Montalvo (2011) examined the pattern of P\&R adoption in Europe, finding that a quarter of cities were strongly engaged in $P \& R$ development and a half moderately engaged. Engagement was stronger to the north and west of the continent compared with the south and east. Overall the spatial pattern of adoption was found to be uneven, despite the fact that the incidence of urban transport problems shows a high degree of consistency across the continent. Based on linear regression analysis the authors argued that the variation reflected the wide diversity of policy frames justifying P\&R development. The most important factors in whether city governments chose to engage in P\&R development or not were found to be: the presence of economic objectives, the extent of citizen demand, and the readiness of organisational learning capabilities. However, overall, these factors explained only around $40 \%$ of the variance. Support for P\&R emerged as qualified; often being the 'second best' choice by administrations, with other measures seen as being more effective in improving accessibility and liveability and P\&R regarded as playing a supporting role within a package of measures.

More recently, in a repeat survey study involving the same cities, Dijk, de Haes and Montalvo (2013) identified similar findings. However a higher degree of variance in extent of engagement (65\%) was explained by the factors of: perceived community pressures for P\&R, economic implications, and organisational capabilities. The authors suggested that greater awareness about the environmental problems associated with transport had encouraged the pressure from citizens. However, local authorities continued to take a less optimistic view of the capabilities of $P \& R$, with $69 \%$ believing that other transport measures would be more effective in addressing environmental issues.

At the UK national level, Meek, Ison and Enoch (2008) found that P\&R has been subject to a series of distinct phases and these have broadly followed the changing sentiments in overall transport policy. The late-1990s saw positive encouragement of P\&R given the UK Government's 'Pragmatic Multimodalism' (Shaw \& Walton, 2001); trying to manage congestion and emissions whilst not appearing to favour particular transport-sector interests. The attention in national policy was relatively short-lived and national policy towards local transport has more recently emphasised decentralisation, with $P \& R$ being one of many measures which authorities can include in applications for national funding for local transport capital investment and travel management packages.

Meek, Ison and Enoch (2010) examined why bus-based P\&R was popular amongst UK local authority officers and councillors through a survey which revealed that a primary motivation for its introduction was that it is identified as a positive 'carrot' policy measure, which presents the authority to the electorate as tackling traffic congestion whilst encouraging the economy; two objectives which are often conflicting in transport policy. A perception was identified amongst policymakers that $P \& R$ is an effective measure for reducing car use. Indeed, $P \& R$ was ranked fifth out of 18 local transport measures for both effectiveness in reducing car use and public acceptability. The evidence about effectiveness in reducing car use will be critically examined in the next section. The initial political appeal of $P \& R$, at least in its bus-based form, was reinforced by its ability to be in the exclusive control of local authorities, sometimes one individual authority.

Indeed, the desire or need to avoid negotiating with other neighbouring authorities is one constraint external to transport policy considerations which encourages the siting of $P \& R$ facilities very close to cities, or indeed within their urban extent, on land under direct planning control and/or ownership 
by the authority ${ }^{3}$. It is also the case that, in the context of a largely deregulated and privatised bus industry in Great Britain (except for London), P\&R services were one of a very few ways in which authorities could continue to exert an element of direct control on urban bus networks ${ }^{4}$.

\section{Evidence on the Effects of P\&R}

Given that $P \& R$ is a complex sociotechnical system, with diverse implementation types, and subject to a wide range of potential policy objectives for implemented schemes, it is important for evidenceled transport planning to be clear about the extent to which the different types of $P \& R$ achieve those policy objectives.

In the case of the UK, by the early 2000s, Parkhurst and Richardson (2002) had concluded, from a review of studies, that the belief that it contributed to overall car traffic reduction was generally contradicted, and that, for the urban areas downstream of P\&R sites, the evidence was variable in terms of the direction of change, and arguably modest in magnitude where a reduction was achieved. Figure 1 indicates these net changes for the eight cities for which extensive data were collected as part of a study for the United Kingdom Government (Harris, Cooper, \& Whitfield, 1998) ${ }^{5}$. These data were subject to further analysis by Parkhurst (2000a). One notable addition to the analysis was the inclusion of the bus traffic generated by the dedicated P\&R service. This was achieved by applying a factor of $2.5 \mathrm{car}-\mathrm{km}$ per bus-km operated, to reflect the higher traffic and environmental impacts of buses over cars, but not taking into account the spatial distribution of congestion or emissions.

\footnotetext{
${ }^{3}$ Such was the case in Oxford in the early 1970s. Oxford City Council had very limited location options for the first two P\&R sites as its transport planning responsibilities ended at an administrative border closely following the extent of urban development. The subregional authority responsible for the surrounding territory, Oxfordshire County Council, was not cooperative in respect of P\&R policy in the early years of its development. Similarly, the subregional Avon County Council had led the development of P\&R in the cities of Bristol and Bath. Since the abolition of that tier of governance in the 1990s, Bath and Northeast Somerset Council, which controls the territory outside of the urban area of Bath has been able to propose additional sites. In contrast, Bristol City Council, which does not even control the entire urban area of the city, has struggled to identify suitable and deliverable additional P\&R site options to the northeast of the city, from which orientation travel demand is highest.

${ }^{4}$ The UK's 1985 Transport Act empowers local authorities to plan and procure bus services which have not been offered on a commercial basis. In practice the service gaps have essentially been in rural areas and at evenings and weekends. $P \& R$ services have generally been a weekday urban exception as they are mostly not commercially viable without local authority support. Operating from a local authority-owned P\&R site does not prohibit a bus operator from registering a commercial service, and this does happen, but in practice a greater degree of informal cooperation is required between operator and authority in order for the service to be attractive to potential users, and therefore viable. Local authorities can impose access charges on commercial bus services using P\&R sites, and they have the choice to impose parking charges on site users. Generally local authorities have sought to recover user contributions from a bus fare rather than by imposing parking charges, as the former are zero-rated for Value Added Tax, whereas parking attracts a standard rate of $20 \%$, paid to central government. Applying parking charges rather than bus fares in order to raise a given level of revenue for local purposes therefore has a higher charge for the traveller. However, a combination of public sector spending cuts and the introduction of free bus travel for citizens of pensionable age has resulted in authorities with high-capacity P\&R schemes (Oxford, York and Cambridge) introducing parking charges in addition to bus fares in order to improve financial performance.

${ }^{5}$ The study team reports case-study selection as arising from a process of assessing 15 candidate cities against 41 transport sector criteria and more pragmatic factors such as context data availability and willingness to participate, with a view to reflecting a range of $P \& R$ experience and type of city in the selected cases.
} 
Figure 1. Changes in traffic arising from P\&R implementations for eight UK cities

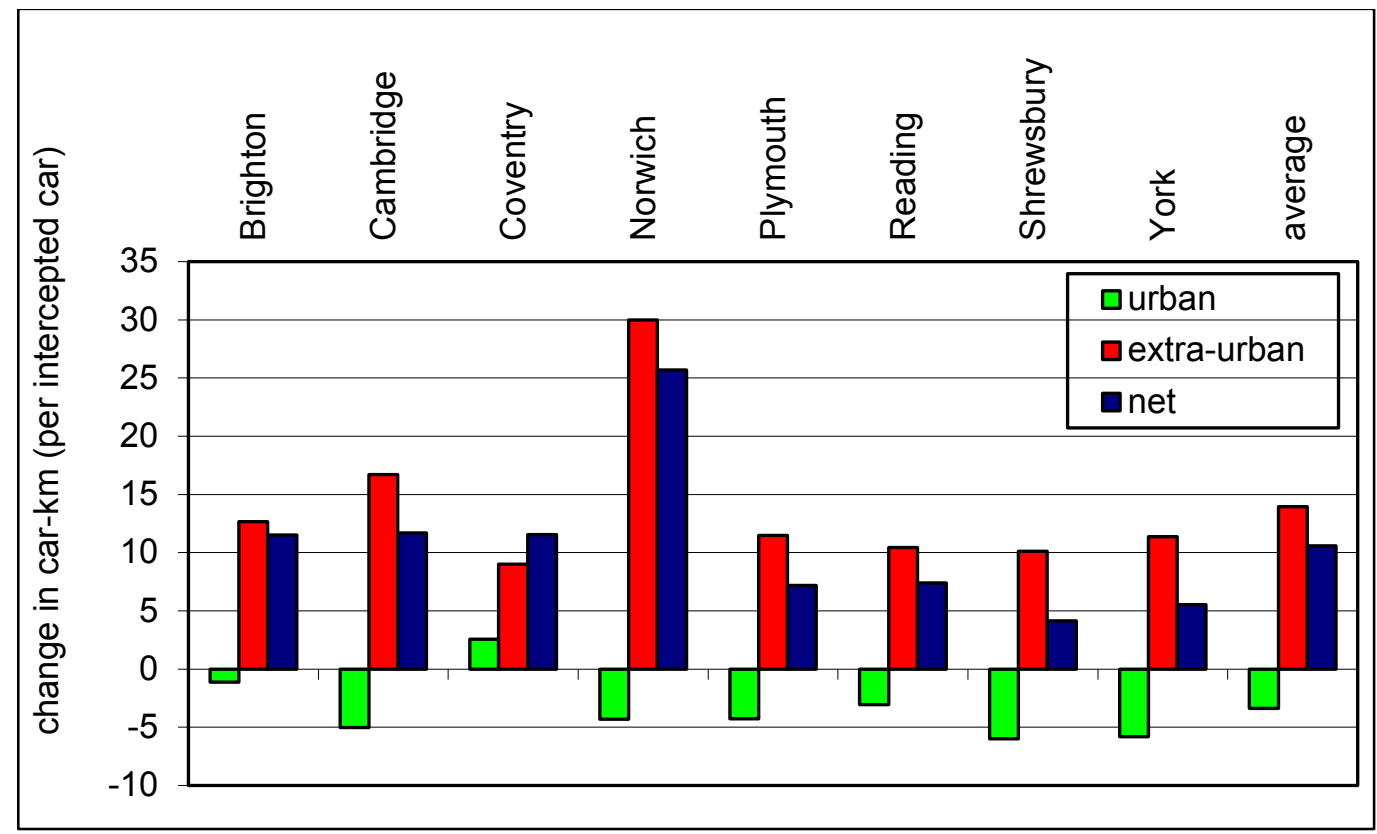

Data from Parkhurst (2000a) Table 8.

Meek, Ison and Enoch (2011) subsequently re-examined the case of Cambridge, following further development of its P\&R facilities, using a higher factor of 3 for bus traffic relative to car traffic, and accounting for the implied alternative travel behaviour of users in more detail. For example, where the alternative was public transport it was assumed that these trips might involve travellers being given lifts to the access point. These refinements produced a lower estimate $(5.9 \mathrm{~km})$ compared to that of Parkhurst (2000a) $(8.8 \mathrm{~km})$, although the P\&R system for Cambridge had changed substantially over the decade between the two studies.

The principal reasons for the findings that bus P\&R overall increased traffic in the UK were that:-

- Nearly all of the schemes examined relied on novel bus services. Therefore, in appraising traffic changes these additional bus movements represent an important offset to the traffic reduction due to car interception.

- Some users choose not to use the P\&R facility which is optimally located for interception, or do not have access to a facility which would shorten their car journeys, and therefore they detour to reach a facility, adding traffic (Parkhurst, 2000a).

- Some P\&R users reduce their public transport use and increase their car use as a result of using $P \& R$, because they did not access the urban area by car before, either walking to public transport or interchanging from car much earlier in the journey (Parkhurst, 1996). A review of perceived alternative modes amongst P\&R users by Meek et al. (2011) showed a range of $9-41 \%$ of $P \& R$ trips would have used public transport in any case, although with important differences between weekday and weekend travel. In terms of magnitude, this effect is important in the overall traffic implications, as the extra-urban public transport journey legs which would provide the alternative option were long with respect to the P\&R public transport legs undertaken within the city (Parkhurst, 2000a). Recent spatial analysis for the city of Bath, UK demonstrates well how public transport 'all the way', interchanging at P\&R sites and driving to the city centre can be substitute journey options (Clayton et al., 2014). Ninety percent of P\&R users had origins within the area shown in Figure $2 a$ and $80 \%$ of car park users originated in the area shown in Figure $2 \mathrm{~b}$. Therefore most users were arriving from locations within $20 \mathrm{~km}$ of Bath. Many of the origins, and particularly in the case of P\&R, were in urban areas which are served by interurban bus services and in some cases rail services as well. 
Figure 2a. Distribution of Bath P\&R Users' Origins

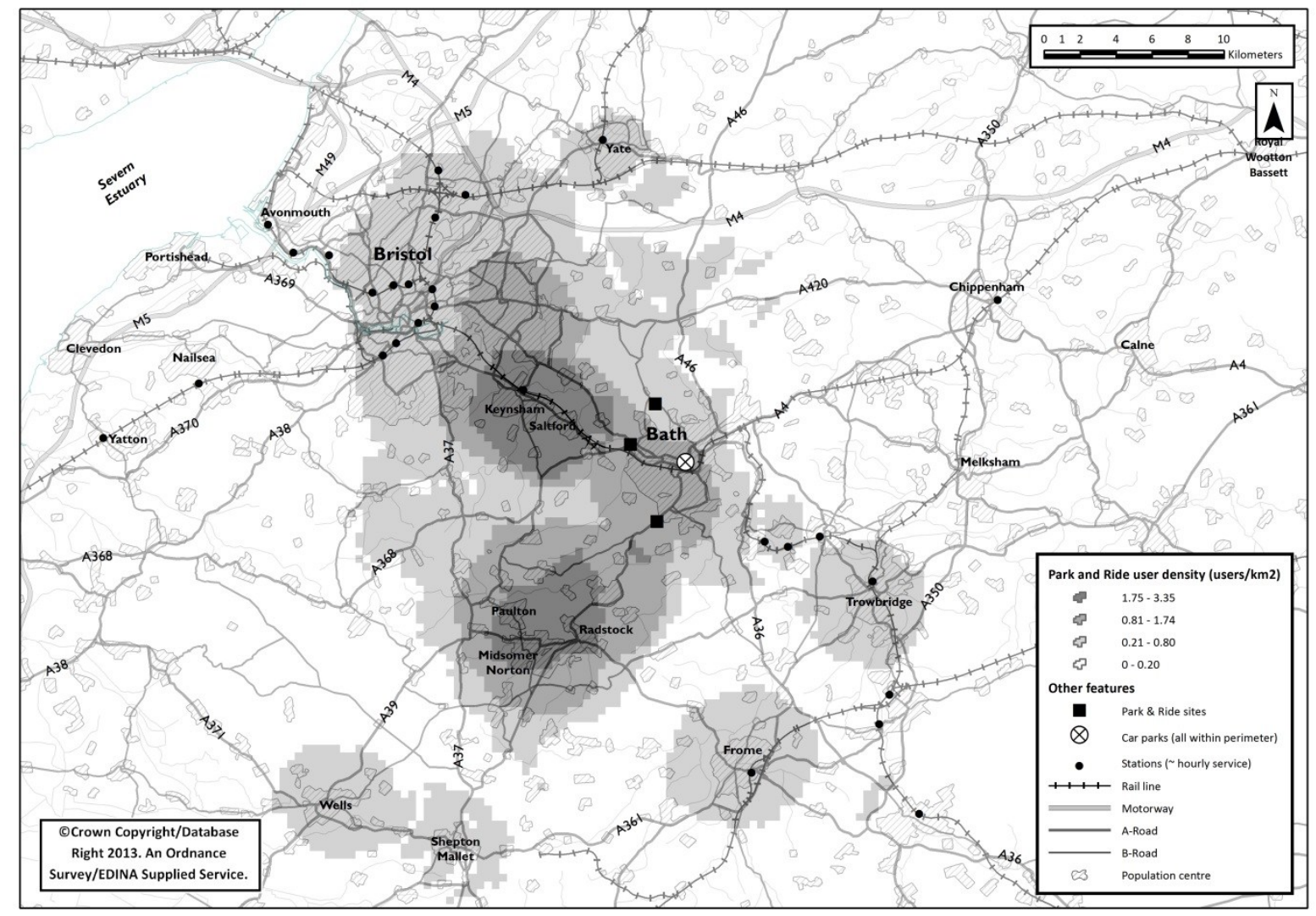

Figure 2b. Distribution of Bath City Centre Car Park users' origins

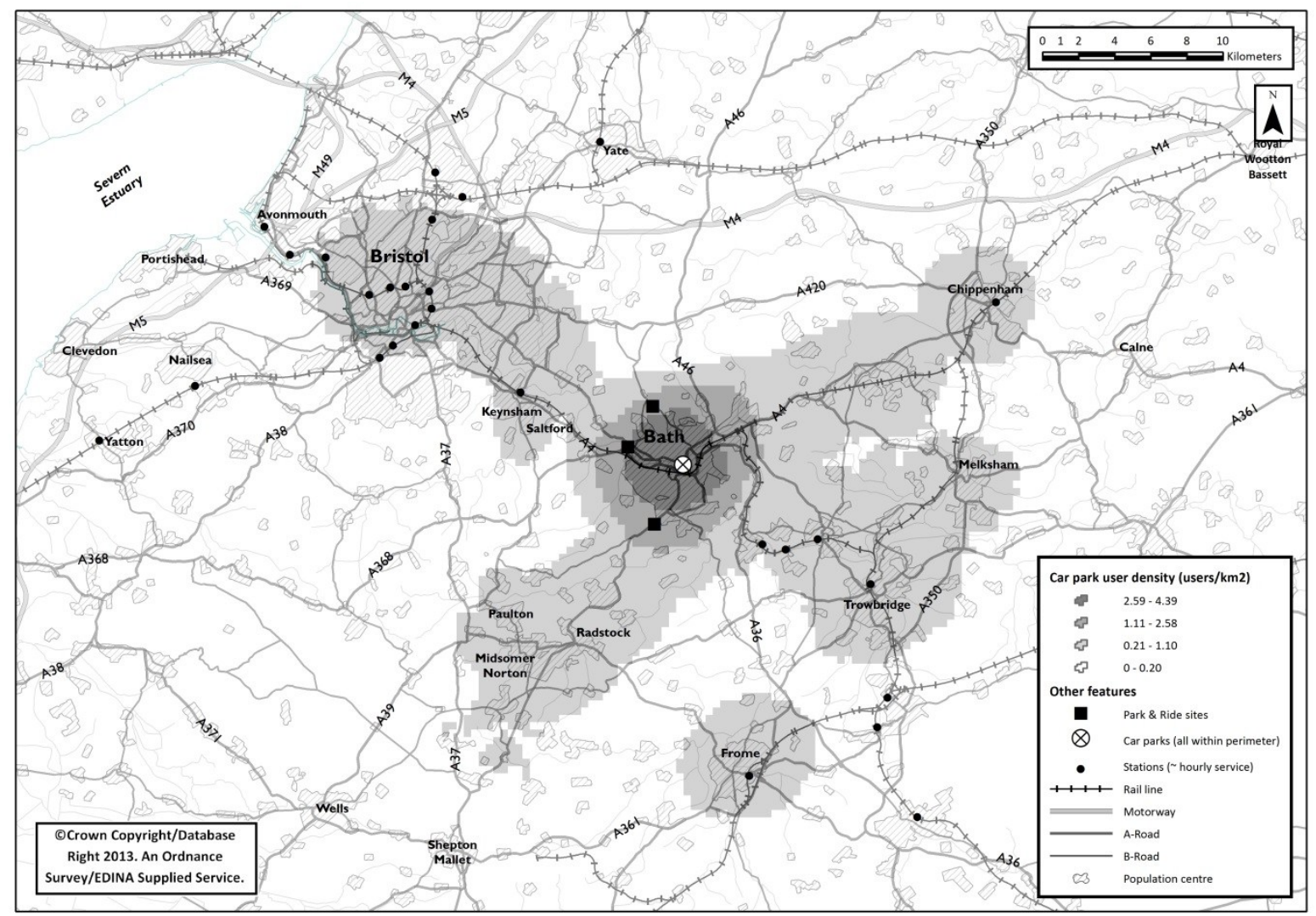


- There was also more tentative evidence that travel rates increase as a result of $P \& R$, because it was offered at a whole-trip cost lower than any of the existing car-based or public transport-based options. Parkhurst (1996) summarised studies which found P\&R users to report a high frequency of visiting the P\&R host city, but it was not clear if these were entirely new or redirected trips. Similarly, both Parkhurst (1996) and Meek et al. (2011) reviewed studies reporting a wide range (1-28\%) in the share of users who had indicated they would not come to the city in the absence of $P \& R$, although given the hypothetical nature of the survey questions it cannot be certain that all these trips would be lost in the absence of $P \& R$, and whether they would be reduced or redirected.

Mingardo (2013) notes two other kinds of 'unintended effect' of P\&R provision. The first of these is a reduction in bicycle use in the Netherlands and Germany and is likely to be a feature in contexts with a high level of cycling. In the UK some local authorities have sought to integrate P\&R and cycling policies by encouraging travellers for whom a cycle trip all the way to the city centre would be too long to instead park cycles rather than cars at the P\&R node. Car-bike trips, whereby a cycle is carried to the $P \& R$ site by car for use on the final journey leg in preference to the $P \& R$ service have also generally been tolerated. The second of Mingardo's findings was the identification of P\&R facilities being used as conventional car parks for journeys completed on foot to destinations nearby. In fact anecdotal evidence of overlapping uses exists from a range of national contexts and is generally unwanted by policymakers, although P\&R has at times been used as a means of enhancing the patronage of poorly used car parks and the sharing of parking activities can occur by intention, for example sports stadia car parks in peripheral locations with high weekend and evening use may be used as weekday commuter P\&R facilities.

To date, most of the empirical studies of P\&R effects have been focussed on bus-based systems (and most of these in Europe) rather than the outcomes of providing P\&R on rail public transport systems. A number of factors may explain this lower profile, including that

- rail systems are often complex, spatially-extensive networks serving multiple destinations,

- the parking capacity has often been added incrementally to railway lines (which themselves predated the rise of car ownership),

- and the fact that rail systems are generally designed to attract access trips by a range of modes.

Bus P\&R, instead, is most often delivered as a novel system of integrated and dedicated parking and public transport services, and has therefore raised more questions about the effects, and effectiveness, of resources specifically allocated to promote interchange.

However, an exception in terms of a study examining local rail $P \& R$ behaviour is that by Mingardo (2013), which surveyed users of nine rail-based P\&R facilities located around the cities of Rotterdam and The Hague in The Netherlands in 2008 and 2009. Given the long-established nature of the facilities, Mingardo found many travellers using the Rotterdam facilities reported that the only alternative to $P \& R$ would be not to travel, as in many cases they had always used the $P \& R$, and so had no 'previous' mode to offer as a potential substitute. Notably, Parkhurst and Stokes (1994) had identified a similar effect in Oxford, surveying bus-based facilities which had been present for 20 years, and these phenomena underline the methodological difficulties with retrospective studies. Table 1 summarises Mingardo's findings, with two other points of note being, in the case of The Hague, further evidence of the significant potential for informal P\&R but also a further mechanism by which cycling can be abstracted; providing attractive station car parking reduces the incentive to cycle to the station. Moreover, it is striking that, in both cases as few as a fifth of respondents saw the alternative for the trip to be a car journey from origin to destination. 
Table 1: Alternative travel behaviour of rail P\&R travellers to Rotterdam and The Hague (\%)

\begin{tabular}{|l|l|l|}
\hline & Rotterdam & The Hague \\
\hline No alternative mode/wouldn't travel & 39 & 2 \\
\hline Car origin to destination & 23 & 19 \\
\hline Public transport near origin to destination & 31 & 37 \\
\hline Cycle origin to destination & 4 & 5 \\
\hline Informal P\&R near PT node & - & 20 \\
\hline Cycle to PT node & - & 17 \\
\hline
\end{tabular}

Data source: Mingardo (2013)

Applying a similar methodology to the UK bus-based studies, Mingardo considered the traffic and emissions implications of the two rail P\&R systems, finding that vehicle-km avoided amounted to only a third of the vehicle-km added for the Rotterdam case, but that around a tenth more were avoided than added in the case of The Hague. Importantly, the key reason for The Hague system resulting in a net reduction was that it was functioning as a 'remote' facility, intercepting travellers from near their destinations, and so reducing the absolute importance of the unintended effects.

In summary, the empirical evidence on the effects of $P \& R$ is limited in terms of the contexts and modes it covers, but is unanimous in confirming that the behavioural responses are much more varied and complex than simply the expected one of intercepting established car trips and thereby shortening them. The outcome that traffic is avoided in the urban area can often, but not always, arise, and where it does occur, the extent of this avoidance may be much lower than might have been assumed, particularly where additional road public transport is operated to provide the $P \& R$ service. Considering system-wide effects, traffic increased overall with only one important exception: rail-based P\&R in The Hague, where travellers interchanged early onto an established, not dedicated, public transport service. This finding will be returned to the final section, considering future policy and planning options for P\&R.

\section{Future Role for P\&R in Strategic Sustainable Development Policy}

The growth of $P \& R$ provision in line with rising use demonstrates that $P \& R$ is a deliverable policy, and attractive to some travellers. However, the behavioural responses discussed above indicate that the outcomes have a closer fit in practice with some of the professional sectorial perspectives than they do with others. Most obviously, P\&R meets the objectives of the local economic development frame, as users report greater willingness to travel and a sense of dependence on P\&R schemes once introduced. In contrast, evidence presents the greatest challenge to the climate change mitigation perspective, given that traffic is generally increased, and that virtually all the vehicles are powered by fossil-fuelled internal combustion engines. The transport operator may perceive the benefits of operating new high-profile services which can attract more 'discretionary' passengers with cars available. However, the evidence suggests system-wide public transport use, considered in terms of passenger-km rather than passenger-trips, may reduce. If the operator is in a commercial environment and has a focus on profitability rather than total patronage, then the relative simplicity and passenger density of $P \& R$ operations may minimise this concern, as may any additional revenues from parking.

The transport and spatial planning perspective requires discussion at greater length. The introduction of P\&R capacity is rarely matched with a reduction in city centre capacity (Dijk \& Parkhurst, 2014), so it generally brings an increase in the total parking stock of host cities. Subject to the regulation and pricing of that parking, other things being equal, greater supply will tend to increase the attractiveness of car accessibility of the city centre. As well as increasing competitiveness with other urban centres, there may also be a relative enhancement of city centre business at the expense of 
neighbouring centres when future business location decisions are made. Similarly, where dedicated P\&R public transport services are offered, a transfer of demand from existing public transport services may occur, which may decrease the viability of those bus and rail routes which lose patronage, and ultimately the business and social communities which depend on them. Ultimately, as suggested in the analysis of effects above, P\&R-dependent spatial forms may be designed or may emerge, so that users would be unable to sustain their established mobility patterns in the absence of P\&R capacity, and spatial forms which would not otherwise be functional are permitted. In addition to the spatial economic concept of the most accessible land being that most desired by commerce, a more practical planning conflict is that $P \& R$ facilities compete for the same space around suburban stations that would otherwise be particularly attractive for the 'transit-oriented development' sought by integrated transport and spatial planning initiatives (Duncan, 2010). Such facilities can also create urban design and environmental impact conflicts through consequences including increased rainwater run-off from the hard surfaces, light intrusion and loss of undeveloped space, and the physical extent of P\&R car parks is often a factor in exacerbating such effects.

Therefore P\&R emerges as having considerable potential influence on travel demand and spatial development. The key policy challenge emerges as to whether it is possible to achieve the outcomes from implementations that support the wider sustainable development agenda, i.e., shortening car trips, supporting overall patronage growth on public transport networks, enhancing low-carbon accessibility, whilst at the same time avoiding the negative effects of stimulating additional traffic, including as a result of attracting users from travel behaviours with lower environmental impacts, and minimising impacts local to the site. Various commentators have identified the need for remote location of the facilities as being central to promoting sustainable interchange facilities (Topp, 1995; Parkhurst, 1995; Meek et al., 2011; Mingardo, 2013). Parkhurst (2000b) and Meek et al. (2011) have also identified the operation of dedicated bus services as a key factor influencing sustainability in the UK context.

Parkhurst (2000b) promoted the 'link and ride' (L\&R) concept for interchange strategy as involving:

- the location of car-bus interchanges relatively far from the final destinations of travellers, meaning that they would need to be located at various spatial ranges,

- the given level of parking capacity to be provided in relatively numerous but small sites to enable proximity to users and minimise environmental impacts, which in turn would be expected to reduce difficulties in site procurement linked to scale,

- the P\&R offer to be on public transport services realistically accessible on foot and by cycle, and

- special subsidies for car users to be avoided, through ensuring users covered the full costs of the P\&R sites and any additional services, and also that the 'market rate' for P\&R should not be lower than the travel alternatives using public transport, walking and cycling. 
Figure 3. Established and alternative concepts for bus P\&R implementation

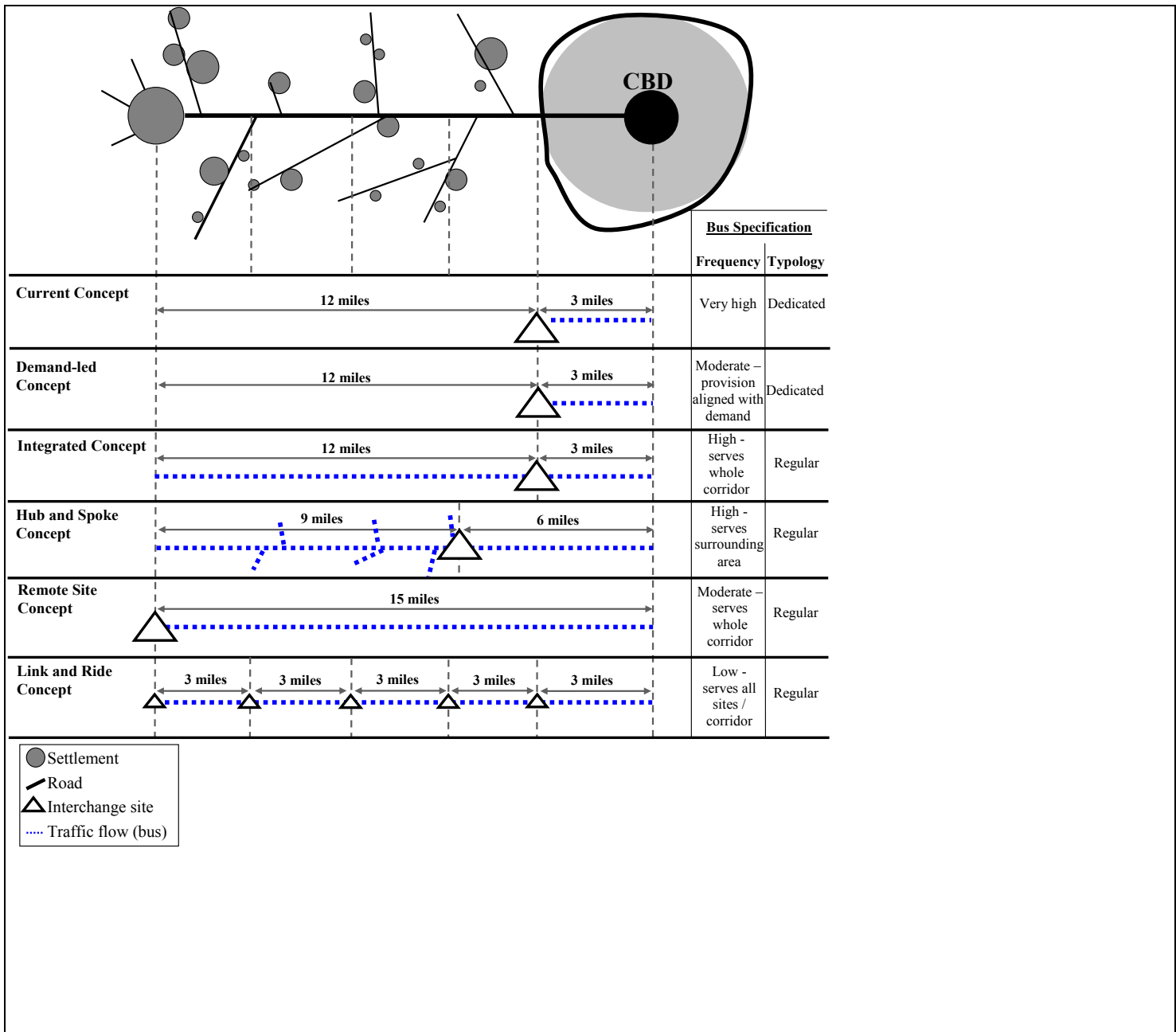

Source: Meek et al. (2011) Figure 1 (with minor amendment).

Meek et al. (2011) further operationalised this approach considering five implementation variants illustrated in Figure 3 and summarised here:-

- Demand-led public transport supply: the service frequency is reduced to 20 minutes between 10:00 and 16:00, to reflect lower demand rather than operating at 10 minute intervals all day, resulting in an increase in wait time and therefore deterring some users, but also increasing mean load factors on the P\&R service and avoiding some bus traffic.

- Integrated concept: uses conventional public transport services routed via a single P\&R facility near the destination, thereby facilitating higher load factors and reducing public transport abstraction.

- Hub and Spoke (H\&S): has similarities with the integrated concept in using general-purpose public transport services and a single P\&R facility, but proposes additional feeder services to the site running on a 20-minute frequency using smaller vehicles, and with the P\&R located intermediately with respect to origins and destinations, with the intention of minimising public transport abstraction and stimulating overall use. The feeders are assumed to be routed so that nearly $40 \%$ of users are within walking range.

- Remote Site: maximises the leg of the trip undertaken on the public transport mode whilst reducing the access distance for a particular cluster of user origins. A medium-frequency (20 minute) bus service is assumed. 
- L\&R: similar to the concept proposed by Parkhurst (2000b) with a chain of sites at approximately $1.5 \mathrm{~km}$ intervals, to reflect the presence of clusters of user origins, and linked by one existing public transport route (Figure 4).

Figure 4. Link-and-Ride scenario applied to Cambridge

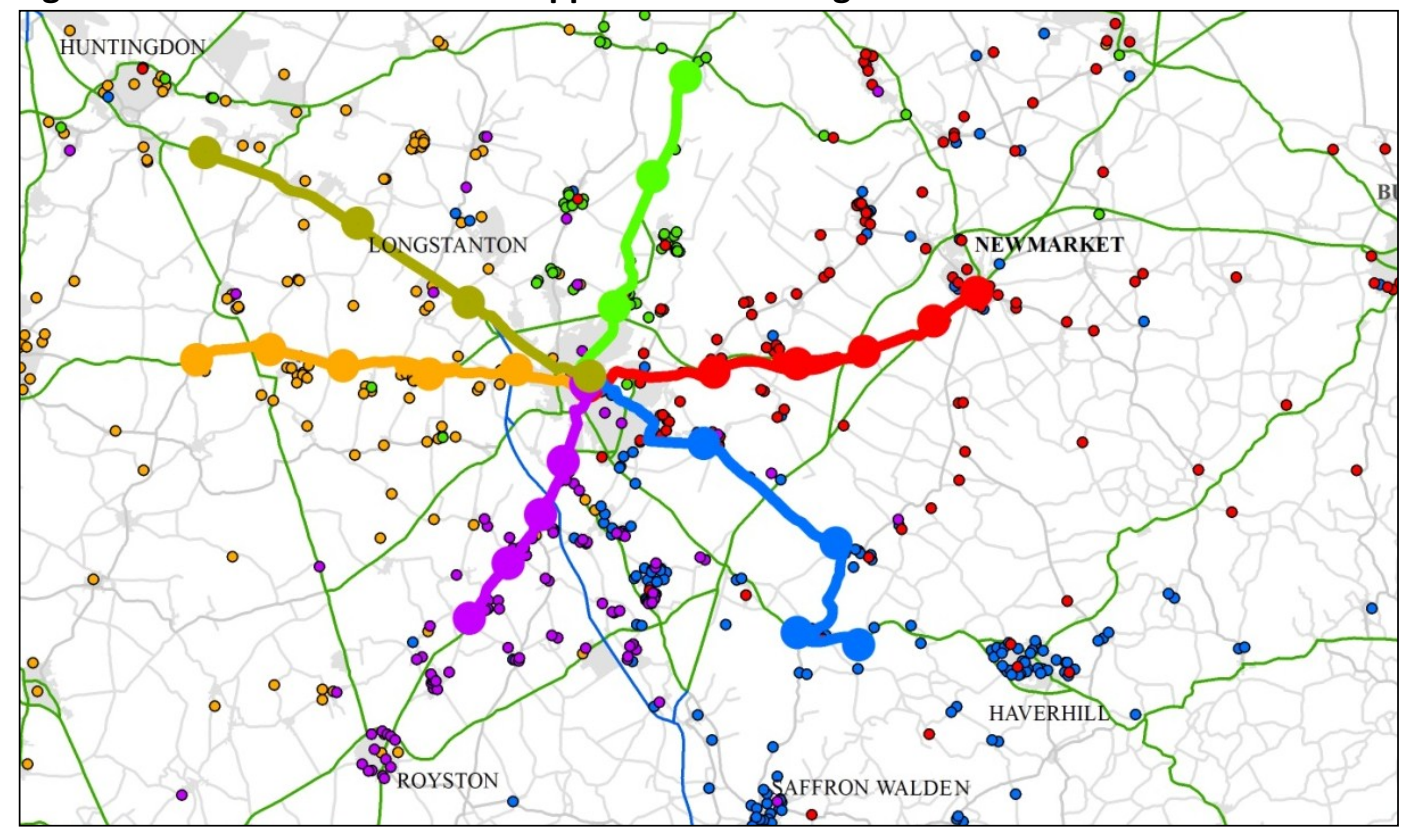

Source: Meek et al. (2011) Figure 7.

The five future scenarios were then subjected to GIS modelling analysis drawing on data relating to the existing P\&R implementations for Cambridge, UK, assuming buses provided the services. A fixed matrix demand, car occupancy and alternative behaviour were assumed, except where P\&R would be added to existing services in the case of L\&R. In the latter case overall demand was assumed to be lower, car occupancy lower, and car used on its own much more likely to be the alternative mode to the interchange trip. The buses used in this scenario were also expected to be smaller, and having a lower environmental impact. The estimated traffic effects are shown in Table 2.

In summary, the findings showed that reducing bus supply in the Demand-led scenario had only a minor effect on traffic changes given the importance of car traffic in the overall analysis, and this not allowing for a likely loss of patronage in response to the reduced level of service. The Integrated and $H \& S$ approaches did indicate lower traffic increases, with the main limitation on the H\&S option being the additional bus traffic created in operating the feeders. These two scenarios could be improved by somewhat reducing bus frequency on the main P\&R service. Moreover, if a level of patronage growth is assumed as a result of the enhanced public transport service offer in the wider network then the H\&S variant indicated the potential to achieve traffic reduction.

Despite the long bus routes, the Remote Site option indicated the second-lowest level of traffic generation, and a modest reduction in bus frequency had the potential to produce a small traffic reduction. However, it emerged as very user-location dependent as the scenario assumed users would be loyal to using a P\&R site located in the same corridor, so some P\&R users living near the city would possibly be travelling away from the destination city and/or further than the current $P \& R$ implementation, in order to access the site. In the Cambridge case, the relatively long car journey legs of the established P\&R users meant this effect was not important. In other contexts the Remote Site approach might potentially generate a more significant level of deviation from shortest path to the city. 
Table 2. Modelled traffic effects of current and alternative interchange concepts (miles)

\begin{tabular}{|l|c|c|c|c|c|c|}
\hline TECHNICAL CHARACTERISTICS & $\begin{array}{c}\text { Current } \\
\text { concept }\end{array}$ & $\begin{array}{c}\text { Demand- } \\
\text { led } \\
\text { concept }\end{array}$ & $\begin{array}{c}\text { Integrated } \\
\text { concept }\end{array}$ & $\begin{array}{c}\text { Hub \& } \\
\text { Spoke } \\
\text { concept }\end{array}$ & $\begin{array}{c}\text { Remote } \\
\text { Site } \\
\text { concept }\end{array}$ & $\begin{array}{c}\text { Link \& } \\
\text { Ride } \\
\text { concept }\end{array}$ \\
\hline Access VMT* (mean) & 24.3 & 24.3 & 22.1 & 16.8 & 18.9 & 3.3 \\
\hline Bus VMT (mean) & 2.1 & 1.6 & 3.64 & 8.8 & 6 & 9.5 \\
\hline Site - centre distance (mean) & 3.26 & 3.26 & 3.26 & 3.26 & 10.6 & 8.7 \\
\hline Daily site usage & 809 & 809 & 809 & 809 & 809 & 479 \\
\hline ALTERNATIVE BEHAVIOUR & & & & & & \\
\hline CAR \% of users & $50 \%$ & $50 \%$ & $50 \%$ & $50 \%$ & $50 \%$ & $86 \%$ \\
\hline Car occupancy (mean) & 1.3 & 1.3 & 1.3 & 1.3 & 1.3 & 1.1 \\
\hline PUBLIC TRANSPORT \% of users & $30 \%$ & $30 \%$ & $30 \%$ & $30 \%$ & $30 \%$ & $5 \%$ \\
\hline Car equivalent factor applied to buses & 2.5 & 2.5 & 2.5 & 2.5 & 2.5 & 2.5 \\
\hline GREEN MODE \% of users & $4 \%$ & $4 \%$ & $4 \%$ & $4 \%$ & $4 \%$ & $0 \%$ \\
\hline GENERATED TRIPS \% of users & $9 \%$ & $9 \%$ & $9 \%$ & $9 \%$ & $9 \%$ & $9 \%$ \\
\hline P\&R USE BEHAVIOUR & & & & & & \\
\hline Car-equivalent factor applied to buses & 3 & 3 & 3 & 3 & 3 & 2.49 \\
\hline Arrived by Car & & & & & & \\
\hline$\%$ of users & $96 \%$ & $96 \%$ & $76 \%$ & $56 \%$ & $75 \%$ & $90 \%$ \\
\hline Car occupancy (mean) & 1.3 & 1.3 & 1.3 & 1.3 & 1.3 & 1.1 \\
\hline Arrived by Green Mode & & & & & & \\
\hline$\%$ of users & $4 \%$ & $4 \%$ & $3 \%$ & $3 \%$ & $18 \%$ & $0 \%$ \\
\hline Arrived by Bus & & & & & & \\
\hline$\%$ of users & $0 \%$ & $0 \%$ & $21 \%$ & $41 \%$ & $7 \%$ & $10 \%$ \\
\hline VMT CHANGE (mean) & & & & & & \\
\hline Base scenario & $\mathbf{3 . 6 8}$ & $\mathbf{3 . 1 6}$ & $\mathbf{2 . 5 4}$ & $\mathbf{2 . 4}$ & $\mathbf{1 . 6 7}$ & $\mathbf{- 7 . 7 5}$ \\
\hline Reduced frequency (15 mins) & - & - & 1.46 & 1.97 & -0.14 & - \\
\hline Plus 27.4 pax p/h per site & 2.50 & - & 1.41 & -0.41 & -0.22 & - \\
\hline
\end{tabular}

*Vehicle-Miles Travelled

Lastly, the L\&R concept, with somewhat different modelling assumptions to reflect the higher degree of integration with existing public transport, was the only case to show significant traffic reduction per user. The salient points in this scenario leading to this reduction were, first, the possibility, as the sites are multiple, to fine-tune the site location with respect to user-origins, so radically reducing the length of access trips, and second, the possibility to increase the patronage on existing bus services to a significant degree, without generating new bus traffic.

\section{Conclusion}

Following the first detailed analyses of the traffic reduction benefits of P\&R schemes in the UK in the 1990s, further studies have continued to confirm the broad findings that, P\&R facilities are often well patronised, but many schemes actually result in a net traffic increase, with evidence recently emerging that some rail-based schemes have similar effects to the bus-based schemes. Hence, they are most likely to be regarded as a success where the objective is not to reduce car use by shortening car trips, but to provide parking where it can more easily and cheaply be made available: on the periphery of a city or at remote railway stations. However, this amounts to an economic strategy to promote further growth within successful cities such as the major commercial centres with intense competition for space and attractive historic cities with protected built environments rather than a sustainable mobility strategy. In addition, formal P\&R policy may sometimes be necessary as a traffic management measure to regularise informal parking, such as around railway stations. 
Related to the traffic-environmental findings, there is some evidence that the enthusiasm for $P \& R$ amongst local authorities in Europe as a whole has been tempered by the realisation that it has limited traffic reduction benefits, and often has a secondary function to support a wider traffic restraint strategy by providing an additional option to travellers. Moreover, the sociotechnical theoretical approach emphasises that, to the extent that P\&R seeks to 'make life easy for the motorist' by providing attractive, frequent, subsidised, 'last-mile' transfers onto priority public transport, the policy will contribute to further developing an automobile culture. Indeed, hitherto, the dominant forms of $P \& R$ have reflected the wider development of transport and land use systems which embody the aspirations and needs of motorists and run counter to the promotion of active travel, transit-oriented development and reducing climate-warming emissions.

However, the chapter has confirmed that many car users are open to considering alternative tripmaking practices including modal interchange. Considerable potential to achieve genuine traffic reduction and more sustainable mobility does exist, provided a number of criteria are met:-

- the overall access and interchange strategy needs to be formulated at a subregional or regional level to ensure the needs of different city economies are considered;

- the strategy should not prioritise car access over other modes, notably the active travel modes and public transport, but seek to involve the car as part of an integrated transport system, with some motorists encouraged to switch from car altogether;

- it should seek to encourage early interchange to the more sustainable modes, so that the traffic and environmental costs of any additional public transport services which are necessary are offset by many motorists making much shorter journeys.

In summary, P\&R needs to be part of a policy package which gradually reforms the regime of automobility towards one of an effective mobility mix, with each mode contributing according to, but not beyond, its particular advantages in sustainable mobility terms. 


\section{References}

Buxton, S., Parkhurst, G., (2005). Towards a truly strategic appraisal process for evaluating park and ride schemes: the development of an assessment framework for London. In Proc. $3^{\text {rd }}$ UK Transport Practitioners Meeting, Aston University, Birmingham, 5-6 July 2005. PTRC, London.

Clayton, B., Ben-Elia, E., Parkhurst, G., \& Ricci, M. (2014). Where to park? A behavioural comparison of bus Park and Ride and city centre car park usage in Bath, UK. Journal of Transport Geography, 36, 124-133.

Dijk, M., Montalvo, C. (2011). Policy frames of Park-and-Ride in Europe. Journal of Transport Geography, 19, 1106-1119.

Dijk, M., de Haes, J., Montalvo, C. (2013). Park-and-Ride motivations and air quality norms in Europe. Journal of Transport Geography, 30, 149-160.

Dijk, M., Parkhurst, G. (2014). Understanding the mobility-transformative qualities of urban park and ride polices in the UK and the Netherlands. Int. J. of Automotive Technology and Management, Special Issue on Sustainable Urban Mobility in Comparison, 14 (3/4), 246-270.

Duncan, M. (2010). To park or to develop: trade-off in rail transit passenger demand. Journal of Planning Education and Research, 30, 162-181.

Harris, C., Cooper, B., \& Whitfield, S. (1998). The travel effects of Park and Ride. Report for United Kingdom Government Department of Environment, Transport and the Regions. Epsom, UK: WS Atkins Planning Consultants.

Heggie, I.G., Papoulias, D. (1976). Operational Performance of Park-and-Ride: Objectives and Achievements in Oxford. Working Paper 23, Transport Studies Unit, University of Oxford.

Horner, M.W., Groves, S. (2007). Network flow-based strategies for identifying rail park-and-ride facility locations. Socio-Economic Planning Sciences, 41, 255-268.

Meek, S., Ison, S., Enoch, M. (2008). Role of bus-based Park and Ride in the UK: a temporal and evaluative review. Transport Reviews, 28 (6), 781-803,

Meek, S., Ison, S., Enoch, M. (2010). UK local authority attitudes to Park and Ride. Journal of Transport Geography, 18, 372 - 381.

Meek, S., Ison, S., Enoch, M. (2011). Evaluating alternative concepts of bus-based park and ride. Transport Policy, 18 (2), 456-467.

Mingardo, G. (2013). Transport and environmental effects of rail-based Park and Ride: evidence from the Netherlands. Journal of Transport Geography, 30, 7-16.

Olowoporoku, D., Hayes, E., Longhurst, J., Parkhurst, G. (2012). The rhetoric and realities of integrating air quality into local transport planning process in English local authorities. Journal of Environmental Management, 101, 23-32.

Papoulias, D., Heggie, I.G. (1976). A Comparative Evaluation of Forecast and Use of Park and Ride in Oxford. Working Paper 22. Transport Studies Unit, University of Oxford.

Parkhurst, G., (1995). Park and ride: could it lead to an increase in car traffic? Transport Policy, 2 (1), 15-23.

Parkhurst, G. (1996). The Economic and Modal-split Impacts of Short-range Park and Ride Schemes: Evidence from Nine UK Cities. ESRC Transport Studies Unit, UCL, report 1996/29.

Parkhurst, G. (2000a). Influence of bus-based park and ride facilities on users' car traffic. Transport Policy, 7 (2) 159-172.

Parkhurst, G. (2000b). Link-and-ride - a longer-range strategy for car-bus interchange. Traffic Engineering and Control, 41 (8), 319-324.

Parkhurst, G., Richardson, J. (2002). Modal integration of bus and car in UK local transport policy: the case for Strategic Environmental Assessment. Journal of Transport Geography, 10 (3), 195-206.

Parkhurst, G., Dudley, G. (2004). Bussing between hegemonies: the dominant frame in Oxford's transport policies. Transport Policy, 11 (1), 1-16.

Parkhurst, G., Kemp, R., Dijk, M., Sherwin, H. (2012). Intermodal personal mobility: a niche caught between two regimes. Chapter 15 in Geels, F., Kemp, R., Dudley, G., Lyons, G. (Eds). Automobility 
in Transition? A Socio-Technical Analysis of Sustainable Transport. Routledge Studies in Sustainability Transitions. New York, USA and London, UK.

Parkhurst, G.P., Stokes, G. (1994). Park and Ride in Oxford and York: Report of Surveys (1994). Working Paper 797, Transport Studies Unit, University of Oxford.

Pickett, M.W., Gray, S.M. (1993). Informal Park and Ride Behaviour in London. Project Report 51, Transport Research Laboratory, Crowthorne.

Shaw, J., Walton, W. (2001). Labour's new trunk-roads policy for England: an emerging Pragmatic Multimodalism? Environment and Planning, 33 (6), 1031-1056.

Schön, D.A., Rein, M. (1994). Frame Reflection: Toward the Resolution of Intractable Policy Controversies. Basic Books, NY.

TAS Partnership (2007). Park \& Ride Great Britain. TAS Partnership, Skipton (fourth edition).

Topp, H.H. (1995). A critical review of current illusions in traffic management and control. Transport Policy, 2 (1), 33-42.

WS Atkins (1998). The Travel Effects of Park and Ride. WS Atkins Planning Consultants, Epsom, for Department of Environment, Transport and the Regions (authors: Harris, C., Cooper, B., Whitfield, S). 